\title{
Feeding a diet devoid of choline to lactating rodents restricts growth and lymphocyte development in offspring
}

\author{
E. D. Lewis ${ }^{1}$, S. Goruk ${ }^{1}$, C. Richard ${ }^{1}$, N. S. Dellschaft ${ }^{1,2}$, J. M. Curtis ${ }^{1}$, R. L. Jacobs ${ }^{1}$ and C. J. Field ${ }^{1 *}$ \\ ${ }^{1}$ Department of Agricultural, Food and Nutritional Science, University of Alberta, Edmonton, T6G 2E1, Canada \\ ${ }^{2}$ Early Life Research Unit, Academic Division of Child Health, Obstetrics \& Gynaecology, School of Medicine, Queen's Medical \\ Centre, The University of Nottingham, Nottingham NG7 2UH, UK
}

(Submitted 20 November 2015 - Final revision received 4 July 2016 - Accepted 5 July 2016 - First published online 2 August 2016)

\section{Abstract}

The nutrient choline is necessary for membrane synthesis and methyl donation, with increased requirements during lactation. The majority of immune development occurs postnatally, but the importance of choline supply for immune development during this critical period is unknown. The objective of this study was to determine the importance of maternal supply of choline during suckling on immune function in their offspring among rodents. At parturition, Sprague-Dawley dams were randomised to either a choline-devoid (ChD; $n$ 7) or cholinesufficient (ChS, $1 \mathrm{~g} / \mathrm{kg}$ choline; $n$ 10) diet with their offspring euthanised at 3 weeks of age. In a second experiment, offspring were weaned to a ChS diet until 10 weeks of age (ChD-ChS, $n 5$ and ChS-ChS, $n$ 9). Splenocytes were isolated, and parameters of immune function were measured. The ChD offspring received less choline in breast milk and had lower final body and organ weight compared with ChS offspring $(P<0.05)$, but this effect disappeared by week 10 with choline supplementation from weaning. ChD offspring had a higher proportion of $\mathrm{T}$ cells expressing activation markers (CD71 or CD28) and a lower proportion of total B cells (CD45RA+) and responded less to T cell stimulation (lower stimulation index and less IFN- $\gamma$ production) ex vivo $(P<0.05)$. ChD-ChS offspring had a lower proportion of total and activated CD4+ T cells, and produced less IL- 6 after mitogen stimulation compared with cells from ChS-ChS $(P<0 \cdot 05)$. Our study suggests that choline is required in the suckling diet to facilitate immune development, and choline deprivation during this critical period has lasting effects on $\mathrm{T}$ cell function later in life.

\section{Key words: Choline: Immunology: Spleen: Lactation period: Growth}

Choline is an essential nutrient required for a variety of critical processes including synthesis of membrane phospholipids and acetylcholine, lipoprotein formation and methyl group metabolism $^{(1)}$. It can be obtained from both dietary and de novo sources, with subclinical symptoms of fatty liver and/or muscle dysfunction resulting from insufficient intake of choline across species ${ }^{(2,3)}$. Choline is widely distributed in food sources, with major sources in the diet reported to include eggs, meat (beef and chicken) and dairy products ${ }^{(4)}$. In the early postnatal period, the need for exogenous choline increases to meet the demands by the infant for rapidly dividing and developing tissues and to account for the depletion of maternal stores ${ }^{(5)}$. Both umbilical $\operatorname{cord}^{(6)}$ and newborn plasma ${ }^{(7)}$ choline concentrations are significantly higher than concentrations in the mother's plasma, suggesting delivery against a concentration gradient to the fetus and infant. Pregnancy and lactation are reported to increase de novo synthesis in rodents ${ }^{(8,9)}$; however, it has been demonstrated that lactating female rodents had greater depletion of liver choline metabolites when fed a choline-deficient (ChD) diet as compared with non-lactating females. This suggests that, although there is greater de novo choline synthesis, this period may result in greater sensitivity to changes in dietary choline intake ${ }^{(10)}$. Despite increased requirements, our recent cohort study found that the majority (90\%) of lactating women were consuming far below the current daily 'adequate intake' recommendations ${ }^{(4)}$, and it is not clear what effects this may have on their children's long-term health. The essentiality of choline in the early postnatal period is well established for many organs including the brain and liver (reviewed by Caudill ${ }^{(11)}$ ). Given the large amount of cellular expansion occurring within the immune system, it is likely that choline plays a critical role in the development of the immune system; however, the effects of maternal choline deprivation during this critical period have not yet been examined.

The early postnatal period is a critical stage for immune system development, with rapid immune cell expansion and proliferation in rodents ${ }^{(12)}$ and humans ${ }^{(13)}$. It is recognised that nutrients modify immune function ${ }^{(14)}$, and this may be of particular importance during the critical development that occurs during the suckling period ${ }^{(13)}$. A study in adult rodents

Abbreviations: CD, cluster of differentiation; ChD, choline-deficient diet; ChS, choline-sufficient diet; ConA, Concanavalin A; LPS, lipopolysaccharide. 
found that feeding a diet without choline (compared with a diet containing $3.5 \mathrm{~g}$ choline $/ \mathrm{kg}$ ) for 8 weeks resulted in lower delayed-type hypersensitivity (DTH) response and proliferation of splenocytes after stimulation with Concanavalin A (ConA $)^{(15)}$. Similarly, we demonstrated that feeding a diet without exogenous choline during the lactation period significantly impaired the function of the maternal immune system and reduced growth of the suckling offspring ${ }^{(16)}$. However, the effect of a maternal diet devoid of choline on the pup's immune system was not measured.

The concept of nutritional programming refers to the effect of environmental factors including diet during a critical period of development on immediate and long-term functions and responses. This concept has not been well established for the development of the immune system, and the potential programming effects of maternal choline intake during the early postnatal period have not been studied. An earlier study found that maternal dietary lipotrope deficiency (choline, methionine and vitamin $\mathrm{B}_{12}$ ) during suckling resulted in depressed $\mathrm{T}$ cell function in the offspring and that it predisposed offspring to bacterial infections (Salmonella typhimurium) in the post-weaning period $^{(17)}$. Another study examining the effects of age on a marginally methionine-choline-deficient diet $(67 \%$ lower in methionine and choline compared with control diet) in weaned rats found that animals at 3 weeks after weaning were most sensitive to methionine-choline deficiency, compared with older animals (12 months after weaning) ${ }^{(18)}$. These studies suggest that lipotrope deficiency during suckling may result in increased susceptibility to infection. However, there are no reported studies examining the effects of choline insufficiency (independent of other methyl donors in the diet) during suckling on immune function later in life.

Our previous study demonstrated that dams fed a diet devoid of choline during lactation negatively affected maternal immune function and impaired pup growth ${ }^{(16)}$. Therefore, the first objective of the present study was to determine the effect of maternal choline deficiency on immune system development in suckled offspring. The secondary objective was to determine whether the intake of choline during lactation would have a programming effect on the development and function of the offspring's immune system later in life. We hypothesised that a choline-deficient maternal diet would be insufficient in supporting the development of the offspring's immune system, and would have lasting effects on the offspring's immune system even if provided a choline-sufficient diet after weaning.

\section{Methods}

\section{Animals and diets}

Expt 1. To examine the effect of maternal choline deficiency on the offspring's immune system development and function, female Sprague-Dawley rats (nineteen rats) were obtained at 14 days of gestation from Charles River Laboratories. All dams were fed a standard rat chow diet (Lab diet 5001; PMI Nutrition International; containing $1 \mathrm{~g}$ choline/kg; Harlan Teklad) throughout pregnancy until parturition. Within $24 \mathrm{~h}$ of birth, dams were randomised to one of two isoenergetic,
Table 1. Composition of experimental diets

\begin{tabular}{lcc}
\hline Components (g/kg diet) & ChS & ChD \\
\hline Casein & 270 & 270 \\
Starch & 241 & 244 \\
Sucrose & 126 & 126 \\
Vitamin mix† & 19 & 19 \\
Mineral mix & 50 & 50 \\
Calcium phosphate dibasic & $3 \cdot 4$ & 3.4 \\
Inositol & $6 \cdot 3$ & $6 \cdot 3$ \\
Cellulose & 80 & 80 \\
L-Cys & $1 \cdot 8$ & $1 \cdot 8$ \\
Flaxseed oil & 7 & 7 \\
Olive oil & 48 & 48 \\
Sunflower oil & 67 & 67 \\
Rapeseed stearin & 78 & 78 \\
DHAsco§ & 1.5 & 1.5 \\
ARAsco§ & 1.5 & 1.5 \\
Choline bitartrate & 2.5 & 0 \\
\% Energy from protein & 25 & 25 \\
\% Energy from carbohydrate & 34 & 34 \\
\% Energy from fat & 41 & 41 \\
Total choline diet (g/kg) & 1.0 & 0 \\
\hline
\end{tabular}

ChS, choline-sufficient diet; ChD, choline-devoid diet.

* All ingredients were purchased from Harlan Teklad, with the exception of the dietary oils that were purchased from Safeway, and rapeseed stearin was donated by Richardson Oilseed Limited.

† American Institute of Nutrition-93-VX vitamin mix $^{(19)}$

$\ddagger$ Bernhart-Tomarelli salt mixture ${ }^{(51)}$.

$\S$ DHAsco is a single-cell oil source of DHA; ARAsco is a single-cell oil source of arachidonic acid.

isonitrogenous and nutritionally adequate diets (Table 1). Diets were fed ad libitum throughout the lactation period until 3 weeks postnatally. Animals had free access to food throughout the study period and feed cups were refilled every $2-3 \mathrm{~d}$.

The two diets differed only in the amount of choline provided (Table 1): ChD (0 g choline/kg diet; $n$ 9) and ChS ( $1.0 \mathrm{~g}$ choline $/ \mathrm{kg}$ diet; $n$ 10). The choline-sufficient diet contained the recommended amount of choline by The Nutrient Requirements of Laboratory Animals ${ }^{(19)}$. This amount of choline $(1 \mathrm{~g} / \mathrm{kg}$ diet) is included in American Institute of Nutrition (AIN)-93 standard rodent diet $\operatorname{mix}^{(19)}$. In humans, the daily recommendation (which is reported as an adequate intake) of choline for lactating women is $550 \mathrm{mg} / \mathrm{d}$. The mean intake in this population of humans is approximately $350 \mathrm{mg} / \mathrm{d}$. We have previously reported that approximately the majority of lactating women (90\%) are estimated to be consuming below what is thought to be the adequate level ${ }^{(4)}$. The diet used in the current study contains what is recommended to meet the needs of pregnant and lactating and growing rodents. At birth, litters were culled to ten offspring (five males and five females when possible) per dam. Dietary intake of dams was recorded throughout the lactation period, and body weight was recorded regularly throughout the study period. This study was concluded at the end of the suckling period ( 3 weeks), and two offspring from each dam were euthanised, with the study design presented in Fig. 1. Two of the dams and their litters from the ChD group were euthanised before the end of the experiment because of significant weight loss and were not included in data analysis making the final $n 7$ for the ChD group. Expt 1 was conducted in two complete blocks in two separate years. The experimental unit in the study was the dam. For each $n$ in the study, we used 


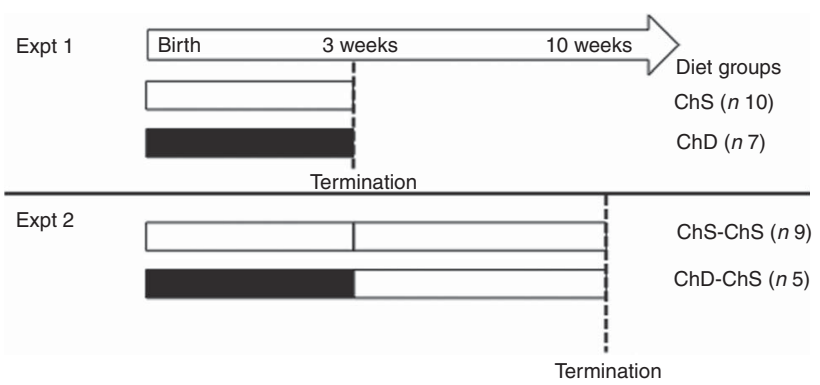

Fig. 1. Experimental study design. Dams were randomly assigned to the choline-sufficient (ChS, $\square$ ) or choline-devoid (ChD, $\square$ ) diets for the duration of the lactation/suckling period. For Expt 1, two offspring (one female and one male) from each dam were terminated at the end of the 3-week suckling period. For Expt 2, two female offspring from each dam were then fed a ChS diet for an additional seven weeks. At 10 weeks, offspring were terminated. The dam represents the experimental unit in this design; therefore, the number of observations within each group is equal to the number of dams, with an average of two offspring per dam for every measurement.

a mean of the measure from two offspring (including one male and one female offspring), and each offspring measure that we report as a unit $(n)$ was the mean of two rodents. The sex of the offspring was not recorded; however, the covariant of variability between the two offspring that we combined for each dam was $<10 \%$ for all the parameters. This suggests that there was no significant effect of sex at this age, similar to what we have previously reported ${ }^{(20)}$.

Expt 2. To investigate whether the amount of choline provided during suckling has a programming effect on immune development and function, a new set of dams were randomised (within $24 \mathrm{~h}$ of giving birth) to the choline-deficient ( $n$, ChD-ChS) or choline-sufficient ( $n$ 9, ChS-ChS) diet (Table 1 ) for 3 weeks, as described in Expt 1. At 3 weeks of age, two female offspring per dam from both the diet groups were weaned to the ChS diet for 7 weeks. All offspring were euthanised at 10 weeks of age (Fig. 1). Rats reach sexual maturity at about 4-5 weeks of age, and therefore female rats in this experiment were sexually mature. Two dams and their litters from the ChD-ChS group were euthanised before the end of the experiment because of significant weight loss and were not included in data analysis making the final $n 5$ for the ChD-ChS group. The institutional and national guidelines for the care and use of animals were followed, and all experimental procedures involving animals were approved by the Committee of Animal Policy and Welfare of the Faculty of Agriculture, Life and Environmental Sciences at the University of Alberta, Edmonton, AB, Canada.

\section{Tissue collection}

At both time points, two offspring from each dam were weighed and euthanised by $\mathrm{CO}_{2}$ asphyxiation in the morning hours. Blood was collected in EDTA-containing tubes via cardiac puncture. Plasma was collected following centrifugation at $3000 \boldsymbol{g}$ for $10 \mathrm{~min}$. Liver and spleen weight and intestinal length were recorded. Spleens were collected aseptically, weighed and immune cells were isolated for further processing (see below). Stomach contents and livers of the offspring were collected aseptically, weighed, snap-frozen using liquid $\mathrm{N}_{2}$ and then stored at $-80^{\circ} \mathrm{C}$ until analysis.

\section{Choline metabolite analyses of offspring stomach content}

The stomach contents of offspring were analysed to reflect the choline content of the dam's milk and to determine the effect of maternal diet on milk content. Frozen stomach contents were ground with liquid $\mathrm{N}_{2}$ and extracted using a modified Bligh and Dyer method that has been described in detail elsewhere ${ }^{(21,22)}$. Extracts were quantified for all significant choline-containing metabolites and total choline content by HILIC liquid chromatography-tandem MS ${ }^{(21,22)}$ using an Agilent 1200 series HPLC system (Agilent Technologies) coupled with a 3200 QTRAP MS (Ab Sciex).

\section{Immune cell isolation}

Isolation of immune cells from the spleen has been previously described $^{(23)}$. In brief, single-cell suspensions were obtained by disrupting tissue through a nylon mesh screen in sterile Krebs-Ringer HEPES buffer with bovine serum albumin $(5 \mathrm{~g} / \mathrm{l}$; Sigma-Aldrich Canada Ltd). Ammonium chloride lysis buffer (155 mm-NH $4 \mathrm{Cl}_{4}$ 0.1 mм-EDTA, 10 mм- $\mathrm{KHCO}_{3}$; Fisher Scientific) was used to lyse erythrocytes. Cells were washed and then re-suspended in complete culture medium (RPMI 1640 media; Life Technologies), supplemented with $5 \%(\mathrm{v} / \mathrm{v})$ heat-inactivated fetal calf serum, 25 mm-HEPES, 2.5 mm-2-mercaptoethanol and $1 \%$ antibiotic/antimycotic ( $\mathrm{pH} 7 \cdot 4$; Fischer Scientific). A haemocytometer was used to count live cells using trypan blue dye exclusion (Sigma-Aldrich) and diluted to $1.25 \times 10^{6}$ cells $/ \mathrm{ml}$.

\section{Immune cell phenotype analysis}

Immune cell subsets present in freshly isolated splenocytes were identified by direct immunofluorescence assay, as previously described $^{(23,24)}$. In brief, 200000 immune cells were incubated for $30 \mathrm{~min}$ at $4^{\circ} \mathrm{C}$ with pre-labelled monoclonal antibodies applied in combination in order to quantify immune cell phenotypes. The use of four-colour flow cytometry allowed identification of the following combinations of surface molecules in Expt 1 and/or Expt 2: CD28/CD3/CD8/CD4 (Expt 1 and 2), CD3/CD45RA/CD27/OX12 (Expt 1 and 2), OX62/OX6/ CD8 (Expt 1 and 2), CD68/CD284/CD11b/c (Expt 1 and 2), CD161/CD3 (Expt 1 and 2), IgG/IgM, IgA, CD3/FOXP3/CD25/ CD4 (Expt 1 and 2), CD25/CD152/CD8/CD4 (Expt 1), CD71/ CD3/CD8/CD4 (Expt 1), CD80/CD152/CD28 (Expt 1), OX12/ OX6/CD27 (Expt 2), CD25CD3/CD4/CD8 (Expt 2) and CD45RA (Expt 2). The CD45RA isoform, also known as leucocyte common antigen, is present only on $\mathrm{B}$ cells in rats ${ }^{(25)}$. All antibodies with the exception of IgG, IgM and OX6 (BD Biosciences) were purchased from Cedarlane Laboratories. After incubation, cells were washed and fixed in paraformaldehyde ( $10 \mathrm{~g} / 1$; Thermo Fisher) in PBS. To identify the intracellular protein forkhead box P3 (FOXP3), an indicator of $\mathrm{T}$ regulatory cells (Treg), isolated cells were permeabilised before antibody addition, according to the manufacturer's directions (Cedarlane Laboratories). All the samples were acquired within $72 \mathrm{~h}$ of preparation by flow cytometry (FACSCalibur; Becton Dickinson) according to the 
relative fluorescence intensity determined using Kaluza Software (Beckman Coulter). From the samples acquired, the total lymphocyte population was gated from the forward-scattered light $v$. side-scattered light plot, and the data presented in the results section represent the percentage of total cells from that mononuclear cell population gate. Representative dot plots illustrating gating for the total mononuclear cell population are shown in the online Supplementary Fig. S1. The online Supplementary Fig. S2 presents the monoclonal antibodies used as isotype controls for flow cytometry analysis, and the online Supplementary Fig. S3 illustrates the unstained splenocytes with the addition of monoclonal antibodies used as isotype controls.

\section{Ex vivo cytokine production by mitogen-stimulated splenocytes}

The measurement of the production of cytokines by mitogenstimulated splenocytes has been previously described ${ }^{(26)}$. In brief, splenocytes $\left(1.25 \times 10^{6}\right.$ cells $\left./ \mathrm{ml}\right)$ were cultured in $3-\mathrm{ml}$ RMPI-1640 medium for $48 \mathrm{~h}$ at $37^{\circ} \mathrm{C}$ and $5 \% \mathrm{CO}_{2}$ without mitogen (unstimulated) or with mitogen ConA $(2.5 \mu \mathrm{g} / \mathrm{ml}$; MP Biomedicals), lipopolysaccharide (LPS, $100 \mu \mathrm{g} / \mathrm{ml}$; SigmaAldrich) or both CD3 $(1 \mu \mathrm{g} / \mathrm{ml})$ and CD28 $(5 \mu \mathrm{g} / \mathrm{ml}$; both from e-Bioscience Inc.). ConA is a polyclonal T-cell stimulant and monoclonal antibodies CD3/CD28 activate the $\mathrm{T}$ cell receptor, with both $\mathrm{CD} 3 / \mathrm{CD} 28$ and ConA stimulating the $\mathrm{T}$ cell population. LPS activates the antigen-presenting cell population including dendritic cells, macrophages and $\mathrm{B}$ cells by binding to their toll-like receptor (CD284). After incubation, cells were centrifuged for $10 \mathrm{~min}$ at $1000 \mathrm{rpm}$, and supernatants were collected and stored at $-80^{\circ} \mathrm{C}$ until analyses. Concentrations of cytokines IL-1 $\beta$, IL-2, IL-6 and IL-10, TNF- $\alpha$ and IFN- $\gamma$ were measured using commercial ELISA kits according to the manufacturer's instructions and as previously described ${ }^{(26)}$. The detection limits for all cytokines were $15 \cdot 6-4000 \mathrm{pg} / \mathrm{ml}$, except for IFN- $\gamma$, for which the detection limit was $9 \cdot 8-2500 \mathrm{pg} / \mathrm{ml}$ (R\&D Systems). Cytokine concentrations were quantified using a microplate reader (SpectraMax 190; Molecular Devices), and all measurements were conducted in duplicates, with CV $<10 \%$. The amount of IL- 2 in the media after LPS stimulation was below detection levels. IL- $1 \beta$ was only measured in the supernatant of LPS-stimulated cells. To express cytokine response by specific lymphocyte population, the percentage of immune cell phenotype (i.e. CD4+ CD25+) was multiplied by $1.25 \times 10^{6}$ (number of total cells added to the culture). Next, cytokine production $(\mathrm{pg} / \mathrm{ml})$ (i.e. IL-2) was divided by the number of lymphocytes added to the culture (i.e. $\times 10^{6}$ of CD $4+\mathrm{CD} 25+$ cells) to express the amount of IL- 2 in the media per a specific lymphocyte subset.

\section{Plasma concentrations of cytokines, chemokines and haptoglobin}

To determine circulating concentrations of cytokines and chemokines in plasma, an electrochemiluminescent multiplex cytokine kit (Proinflammatory Panel 1 V-PLEX; MesoScale Discovery) was used. IFN- $\gamma$, IL-10, IL-13, IL-1 $\beta$, IL-2, IL-4, IL-5, IL-6, TNF- $\alpha$ and KC/GRO (keratinocyte chemoattractant/human growth-regulated oncogene also known as CXCL1, chemokine ligand 11) were measured according to the manufacturer's instructions. In brief, standards and samples $(50 \mu \mathrm{l} /$ well $)$ were added in duplicate to a plate pre-coated with capture antibody for each cytokine. Plates were incubated for $2 \mathrm{~h}$ at room temperature on a plate shaker. Plates were then washed with wash buffer (3x PBS with $0.05 \%$ Tween 20). Detection antibody was added and incubated for an additional $2 \mathrm{~h}$. Plates were then washed with wash buffer $(3 x)$ and a read buffer was added. Plates were read on the MSD Sector Image 6000 (MesoScale Discovery), and all measurements were conducted in duplicates. The lower levels of detection limits were $0.65 \mathrm{pg} / \mathrm{ml}$ (IFN- $\gamma), \quad 16.4 \mathrm{pg} / \mathrm{ml} \quad$ (IL-10), $1.97 \mathrm{pg} / \mathrm{ml} \quad$ (IL-13), $6.92 \mathrm{pg} / \mathrm{ml}$ (IL-1 $\beta), 0 \cdot 69 \mathrm{pg} / \mathrm{ml}$ (IL-4), $14 \cdot 1 \mathrm{pg} / \mathrm{ml}$ (IL-5), $13 \cdot 8 \mathrm{pg} / \mathrm{ml}$ (IL-6), $0.72 \mathrm{pg} / \mathrm{ml}(\mathrm{TNF}-\alpha)$ and $1.04 \mathrm{pg} / \mathrm{ml}(\mathrm{KC} / \mathrm{GRO})$.

Plasma haptoglobin concentrations were determined using a colorimetric assay according to the manufacturer's instructions (Tridelta Development). The detection limit for haptoglobin was $0.312 \mathrm{mg} / \mathrm{ml}$. All measurements were conducted in duplicates, with $\mathrm{CV}<10 \%$. Among the 3-week offspring, discrepancies between total number of offspring $(n 17)$ and the number available for measurements ( $n$ 12) of haptoglobin, TNF- $\alpha$ and KC/GRO were due to clotting of the sample, preventing the processing of those samples.

\section{Estimation of lymphocyte proliferation in the absence and presence of mitogens in spleen}

In a subset of 3-week-old animals (five dams), proliferation was estimated by the rate of $\left[{ }^{3} \mathrm{H}\right]$ thymidine (Amersham/Pharmacia Biotech) uptake by spleen lymphocytes $\left(1.25 \times 10^{6} / \mathrm{ml}\right)$ in the presence or absence of mitogens. Lymphocytes were cultured for $48 \mathrm{~h}$ in ninety-six-well plates with or without mitogens, as previously described ${ }^{(27)}$. The mitogens used were ConA $(2.5 \mu \mathrm{g} / \mathrm{ml}$; MP Biomedicals), LPS $(100 \mu \mathrm{g} / \mathrm{ml}$; Sigma-Aldrich) or both CD3 $(1 \mu \mathrm{g} / \mathrm{ml})$ and CD28 $(5 \mu \mathrm{g} / \mathrm{ml}$; both from e-Bioscience Inc.). Each well was pulsed with $0.037 \mathrm{MBq}$ of $\left[{ }^{3} \mathrm{H}\right]$ thymidine for $18 \mathrm{~h}$ before collecting cells. Proliferation due to LPS was not measured as in our ex vivo conditions as it does not stimulate IL-2 production by splenocytes. All assays were conducted in triplicate for each offspring and two offspring were pooled to obtain a measure of each dam. Stimulation index for each mitogen condition was calculated as follows: amount of $\left[{ }^{3} \mathrm{H}\right]$ thymidine uptake $(\mathrm{dpm})$ in the presence of each mitogen divided by the amount of $\left[{ }^{3} \mathrm{H}\right]$ thymidine uptake $(\mathrm{dpm})$ in the absence of each mitogen. Lymphocyte proliferation was not measured in 10-week-old animals as there was no difference in IL-2 production following ConA stimulation.

\section{Statistical analyses}

All data are presented as means with their standard errors, unless otherwise noted. As the dam was the experimental unit $(n)$, each $n$ in the data is the mean of two offspring per dam. All measurements were conducted in duplicate or triplicate for each offspring. All data sets were tested for normal distribution using the Kolmogorov-Smirnov test. Parametric data were then analysed for differences using two-tailed $t$ test. Non-parametric data were log-transformed before analysis, and then a two-tailed $t$ test was performed. In some cases, 
log-transformation of the data did not lead to normal distribution; therefore, groups were analysed using the Mann-Whitney $U$ test. Expt 1 was conducted over 2 years; therefore, we included year as a blocking variable in all analyses. Year was a blocking variable as it was not a variable of interest, but the variability due to the experiments being conducted over 2 years must be taken into account. There was no difference between years (in the block); therefore, data are illustrated as a combination of both years. Statistical analyses were performed using SPSS Statistics (version 21; IBM) and SAS statistical software (version 9.3; SAS Institute Inc.), with a $P$ value of $<0.05$ considered to be statistically significant for all analyses.

\section{Results}

\section{Anthropometric characteristics and total choline stomach content}

For Expt 1, two dams and their litters from the $\mathrm{ChD}$ group were euthanised before the end of the experiment because of significant weight loss and were not included in data analysis, making the final $n 7$ for the ChD group. In Expt 1, 3-week-old offspring from $\mathrm{ChD}$ dams that survived had mean lower body weight, liver weight and intestine length compared with offspring from the ChS dams (Table 2). Although spleen weight was not significantly different between diet groups, ChD offspring had indications of lymphopenia as demonstrated by a significantly lower number of splenocytes compared with ChS offspring $(P<0.05)$ (Table 2$)$. ChD dams began to consume significantly lower amounts of food beginning on postnatal day 9, which is likely when they started to be deficient in choline. As previously reported, at $21 \mathrm{~d}$ postnatally, the $\mathrm{ChD}$ dams weighed $17 \%$ less and their food intake was $29 \%$ lower compared with ChS dams ${ }^{(16)}$.

ChD offspring had a significantly lower total choline concentration in the stomach contents compared with ChS offspring (Table 2). The relative proportion of choline metabolites that contributed to total choline was also different between diets and has been previously reported by Dellschaft et $a l^{(16)}$.

Table 2. Anthropometric data of 3-week-old offspring from dams fed choline-sufficient (as free choline) (ChS) or choline-devoid (ChD) diets during the suckling period $\dagger$ (Mean values with their standard errors)

\begin{tabular}{|c|c|c|c|c|}
\hline \multirow[b]{2}{*}{$n \ddagger$} & \multicolumn{2}{|c|}{ ChS (10) } & \multicolumn{2}{|c|}{ ChD (7) } \\
\hline & Mean & SEM & Mean & SEM \\
\hline Body weight (g) & 40 & 3 & $28^{\star}$ & 2 \\
\hline Spleen weight $(\mathrm{g})$ & 0.2 & 0.02 & 0.2 & 0.01 \\
\hline Splenocytes/g spleen $\left(\times 10^{6}\right)$ & 744 & 46 & $539^{*}$ & 13 \\
\hline Liver weight $(\mathrm{g})$ & 1.7 & 0.1 & $1 \cdot 1^{*}$ & 0.1 \\
\hline Liver fat weight (mg/g liver) & 37 & 5 & 34 & 1 \\
\hline Intestine length $(\mathrm{cm})$ & 63 & 2 & $54^{\star}$ & 2 \\
\hline Stomach total choline content $(\mathrm{mg} / 100 \mathrm{~g})$ & $13 \cdot 1$ & 1.2 & $6 \cdot 2^{*}$ & 1.0 \\
\hline
\end{tabular}

* Mean values within a row are significantly different compared with the ChS group $(P<0.05)$.

† At birth, litters were standardised to ten offspring per dam consisting of five males and five females when possible. Measurements collected at 3 weeks were pooled from one male and one female per dam.

$\ddagger n$ Refers to the number of dams as they are the experimental unit. This includes two offspring pooled to obtain a measure for each dam, with measurements from each offspring conducted in duplicate.
For Expt 2, two dams and their litters from the ChD-ChS group were euthanised before the end of the experiment due to significant weight loss and were not included in data analysis, making the final $n 5$ for the ChD-ChS group. ChD-ChS offspring had lower body weight at weaning $(P<0.05)$ (Table 3 ). However, after being placed on a ChS diet for the remaining 7 weeks, final body weight was not significantly different compared with ChS-ChS offspring. Food intake, spleen and liver weight, and intestinal length were not significantly different between diet groups at the end of 10 weeks.

\section{Splenocyte immune cell phenotypes}

The phenotypes presented represent a proportion of the total mononuclear cell population that was gated from acquired splenocytes (online Supplementary Fig. S1). The histograms (online Supplementary Fig. S2) and unstained splenocytes with isotype controls (online Supplementary Fig. S3) demonstrate that there was no non-specific binding in our acquired samples. Consistent with the indications of lymphopenia, ChD offspring had $27 \%$ lower total number of $\mathrm{T}$ lymphocytes (CD3+) and $47 \%$ lower total number of B lymphocytes (CD 45RA+) in the spleen compared with ChS offspring $(P<0.05)$ (Table 4$)$. When examined as a proportion of gated cells, ChD offspring had a higher proportion of CD4+ and CD8+ T cells, which resulted in a significantly higher ratio of $\mathrm{T}$ cells (CD3+):B cells (CD45RA+) (Table 4). Although having a significantly lower total amount of lymphocytes, assessment of activation markers on $\mathrm{T}$ cells (CD25, CD28, CD152) indicated that ChD offspring had a higher proportion of CD4+ $\mathrm{T}$ cells expressing CD28+ and a higher proportion of CD8+ T cells expressing C28 and CD152 cells compared with ChS offspring $(P<0.05)$ (Table 5). There was also a significantly higher proportion of CD4+ and CD8+ cells expressing the proliferation marker CD71 (transferrin receptor) compared with ChS offspring $(P<0 \cdot 05)$ (Table 5). There was no significant difference in the proportion of FoxP3 + CD25+ cells within the CD4+ $\mathrm{T}$ cell population, representing putative Treg cells, between the diet groups (Table 5). There was also a

Table 3. Anthropometric data from 10-week-old offspring fed a cholinesufficient (as free choline) diet for 10 weeks (ChS-ChS) or offspring from dams fed a choline-devoid diet during the suckling period and then fed a choline-sufficient diet for the remaining 7 weeks (ChD-ChS) $\dagger$ (Mean values with their standard errors)

\begin{tabular}{lcccccc}
\hline & \multicolumn{2}{c}{ ChS-ChS $(9)$} & & \multicolumn{2}{c}{ ChD-ChS (5) } \\
\cline { 2 - 3 } \cline { 6 - 7 }$n$ & Mean & SEM & & Mean & SEM \\
\hline Body weight at weaning (4 weeks) $(\mathrm{g})$ & 76 & 4 & & $61^{*}$ & 4 \\
Final body weight (10 weeks) $(\mathrm{g})$ & 267 & 9 & & 266 & 15 \\
Food intake $(\mathrm{g} / \mathrm{d})$ & 23 & 1 & & 23 & 2 \\
Spleen weight $(\mathrm{g})$ & 0.62 & 0.03 & & 0.65 & 0.1 \\
Splenocytes/g spleen $\left(\times 10^{6}\right)$ & 464 & 40 & & 493 & 40 \\
Liver weight $(\mathrm{g})$ & 9.0 & 0.3 & & $9 \cdot 1$ & 0.4 \\
Intestine length $(\mathrm{cm})$ & 118 & 2 & & 117 & 1 \\
\hline
\end{tabular}

* Mean value within a row is significantly different from the ChS-ChS group $(P<0.05)$.

† At birth, litters were standardised to ten offspring per dam consisting of five males and five females when possible. Measurements collected at 10 weeks were from females only.

$\ddagger n$ Refers to the number of dams as they are the experimental unit. This includes two offspring pooled to obtain a measure for each dam, with measurements from each offspring conducted in duplicate. 
Table 4. Proportion and the total number of $T$ and $B$ lymphocyte populations in the spleen from 3-week-old offspring from dams fed choline-sufficient (as free choline) (ChS) or choline-devoid (ChD) diets during the suckling period (Mean values with their standard errors)

\begin{tabular}{|c|c|c|c|c|c|c|c|c|}
\hline \multirow[b]{3}{*}{$n \ddagger$} & \multicolumn{4}{|c|}{$\%$ of total lymphocytes } & \multicolumn{4}{|c|}{ Total number of immune cells $\left(\times 10^{6}\right) \dagger$} \\
\hline & \multicolumn{2}{|c|}{ ChS (10) } & \multicolumn{2}{|c|}{ ChD (7) } & \multicolumn{2}{|c|}{ ChS (10) } & \multicolumn{2}{|c|}{$\mathrm{ChD}(7)$} \\
\hline & Mean & SEM & Mean & SEM & Mean & SEM & Mean & SEM \\
\hline Total CD3+ & $22 \cdot 3$ & $1 \cdot 1$ & $27 \cdot 7^{\star}$ & $1 \cdot 1$ & $32 \cdot 3$ & 3 & $23 \cdot 7^{\star}$ & 2 \\
\hline CD3+ CD4+ & 11 & $0 \cdot 8$ & $13 \cdot 9^{*}$ & 0.9 & $16 \cdot 3$ & $2 \cdot 1$ & $12 \cdot 3$ & $1 \cdot 8$ \\
\hline CD3+ CD8+ & $9 \cdot 3$ & 0.5 & $12 \cdot 7^{\star}$ & 0.6 & $14 \cdot 1$ & 2 & $10 \cdot 9$ & $1 \cdot 1$ \\
\hline Total CD45RA+ & $59 \cdot 7$ & 0.8 & $54 \cdot 9^{*}$ & $1 \cdot 7$ & 88.9 & $11 \cdot 1$ & $47 \cdot 5^{\star}$ & 4.6 \\
\hline CD3+:CD45+ ratio & 0.37 & 0.01 & $0.51^{*}$ & 0.02 & 0.38 & 0.03 & $0.51^{*}$ & 0.02 \\
\hline Total IgM+ & 63.8 & 1.3 & $63 \cdot 1$ & $2 \cdot 8$ & $85 \cdot 0$ & $7 \cdot 8$ & $54 \cdot 4^{\star}$ & $5 \cdot 3$ \\
\hline Total lgG+ & $7 \cdot 0$ & 0.9 & $10 \cdot 9^{\star}$ & 0.8 & $11 \cdot 9$ & $3 \cdot 4$ & $9 \cdot 2$ & 4.6 \\
\hline
\end{tabular}

$\mathrm{CD}$, cluster of differentiation.

* Indicates mean within a row that is significantly different from the ChS group $(P<0.05)$.

$\dagger$ The total number of immune cells was calculated by multiplying the percentage of immune cell phenotype in the spleen by the total number of splenocytes isolated $\left(\times 10^{6}\right)$.

$\ddagger n$ Refers to the number of dams as they are the experimental unit. This includes two offspring pooled to obtain a measure for each dam, with measurements from each offspring conducted in duplicate.

Table 5. Splenocyte T and B lymphocyte phenotypes from 3-week-old offspring from dams fed choline-sufficient (as free choline) (ChS) or choline-devoid $(\mathrm{ChD})$ diets during the suckling period (Mean values with their standard errors)

\begin{tabular}{|c|c|c|c|c|c|}
\hline \multirow[b]{2}{*}{$n \dagger$} & \multicolumn{2}{|c|}{ ChS (10) } & \multicolumn{2}{|c|}{$\mathrm{ChD}(7)$} & \multirow[b]{2}{*}{ Representative population } \\
\hline & Mean & SEM & Mean & SEM & \\
\hline & \multicolumn{4}{|c|}{$\%$ of CD4+ T cells } & \\
\hline CD25+ & 11.7 & $2 \cdot 2$ & $14 \cdot 3$ & 3.1 & CD4+ T cells expressing IL-2 receptor \\
\hline CD28+ & $77 \cdot 8$ & 3.9 & $91 \cdot 2^{*}$ & $3 \cdot 3$ & CD4+ T cells expressing co-stimulatory molecule \\
\hline CTLA-4+ (CD152+) & 9.5 & 1.3 & $12 \cdot 3$ & $1 \cdot 1$ & CD4+ $T$ cells expressing cytotoxic $T$ lymphocyte associated protein 4 \\
\hline $\mathrm{CD} 71+$ & 20.9 & 1.4 & $27 \cdot 4^{*}$ & 1.3 & CD4+ $T$ cells expressing the transferrin receptor \\
\hline$a \mathrm{E} \beta 7+(\mathrm{O} \times 62+)$ & 9.5 & 1.2 & 10.5 & 0.7 & CD4+ $T$ cells with gut homing potential expressing the $a$ E2 integrin \\
\hline \multirow{2}{*}{ CD25+ FoxP3+ } & 10.5 & 3.7 & $12 \cdot 1$ & 4.7 & Regulatory T cells \\
\hline & \multicolumn{4}{|c|}{$\%$ of CD8+ T cells } & \\
\hline CD25+ & 12.5 & 1.2 & $16 \cdot 9^{*}$ & 2.4 & CD8+ T cells expressing IL-2 receptor \\
\hline CD28+ & $72 \cdot 8$ & 1.9 & $75 \cdot 5$ & 3.0 & CD8+ $T$ cells expressing co-stimulatory molecule \\
\hline CTLA-4+ (CD152+) & $19 \cdot 3$ & $2 \cdot 7$ & 29.2 & $5 \cdot 6$ & CD8+ T cells expressing cytotoxic T lymphocyte-associated protein 4 \\
\hline CD71+ & 34.9 & $2 \cdot 4$ & $50 \cdot 3^{*}$ & 4.7 & $C D 8+T$ cells expressing the transferrin receptor \\
\hline \multirow[t]{2}{*}{$\alpha \mathrm{E} \beta 7+(\mathrm{OX} 62+)$} & $10 \cdot 6$ & 1.2 & 10.3 & 0.8 & $\mathrm{CD} 8+\mathrm{T}$ cells with gut-homing potential expressing the $a \mathrm{E} 2$ integrin \\
\hline & \multicolumn{4}{|c|}{$\%$ of CD45RA+ B cells } & \\
\hline CD27+ & 94.1 & $1 \cdot 2$ & 94.0 & 1.4 & B cells expressing a member of the TNF-superfamily indicating memory cells \\
\hline $\mathrm{MHCll}+(\mathrm{OX} 6+) \ddagger$ & 79.6 & 2.5 & $91 \cdot 9^{*}$ & $2 \cdot 9$ & B cells with antigen-presenting capacity expressing MHC Class II \\
\hline
\end{tabular}

$\mathrm{CD}$, cluster of differentiation.

${ }^{*}$ Mean values within a row is significantly different from ChS group $(P<0.05)$.

$\dagger n$ Refers to the number of dams as they are the experimental unit. This includes two offspring pooled to obtain a measure for each dam, with measurements from each offspring conducted in duplicate.

$\ddagger \%$ of CD45RA+ cells expressing OX6+ calculated using total OX6+ cells -OX6+OX62+ to represent population of CD45RA+cells expressing OX6+.

higher proportion of B cells (CD45RA+) with antigen-presenting capacity (OX6+) in ChD offspring compared with ChS offspring $(P<0.05)$ (Table 5).

In Expt 2, feeding a choline-sufficient diet to offspring fed a choline-devoid diet during the suckling period (ChD-ChS offspring) rescued the lymphopenic status, as demonstrated by similar numbers of splenocytes (Table 3 ) and proportion of total $\mathrm{T}$ cells (CD3+) in the spleen between both groups of 10-weekold offspring (Table 6). However, ChD-ChS offspring still had a slight shift in lymphocyte proportions as there was a lower proportion of CD4+ T cells, compared with ChS-ChS offspring $(P<0.05)$ (Table 6). ChD-ChS offspring also had a significantly lower proportion of CD8+ T cells expressing activation marker
CD28 (co-stimulatory molecule) (Table 7). ChD-ChS offspring also had a lower proportion of IgA+ cells in the spleen, yet there was no significant difference in the proportion of total $\mathrm{B}$ cells (CD45RA+) between groups at 10 weeks (Table 6).

\section{Ex vivo response to stimulation by splenocytes}

At 3 weeks, the absolute rate of $\left[{ }^{3} \mathrm{H}\right]$ thymidine uptake in the presence of mitogen (ConA or CD3/CD28) or absence of mitogen (unstimulated) was used to calculate the stimulation index. ChD offspring had a significantly lower stimulation index following ConA stimulation compared with ChS offspring $(P<0.05)$ (Fig. 2). When equal numbers of splenocytes were 
Table 6. Proportion and the total number of $T$ and $B$ lymphocyte populations in spleen from 10-week old offspring fed a cholinesufficient (as free choline) diet for the duration of the 10 weeks (ChS-ChS) or offspring from dams fed a choline-devoid diet during the suckling period then fed a choline-sufficient diet for the remaining 7 weeks (ChD-ChS) (Mean values with their standard errors)

\begin{tabular}{|c|c|c|c|c|c|c|c|c|}
\hline \multirow[b]{3}{*}{$n \ddagger$} & \multicolumn{4}{|c|}{$\%$ of total lymphocytes } & \multicolumn{4}{|c|}{ Total number of immune cells $\left(\times 10^{6}\right) \dagger$} \\
\hline & \multicolumn{2}{|c|}{ ChS-ChS (9) } & \multicolumn{2}{|c|}{ ChD-ChS (5) } & \multicolumn{2}{|c|}{ ChS-ChS (9) } & \multicolumn{2}{|c|}{ ChD-ChS (5) } \\
\hline & Mean & SEM & Mean & SEM & Mean & SEM & Mean & SEM \\
\hline Total CD3+ & 41.0 & 2 & $40 \cdot 7$ & 1.5 & $115 \cdot 8$ & 9.6 & $127 \cdot 9$ & 13.5 \\
\hline CD3+ CD4+ & 20.5 & 1.2 & $16 \cdot 5^{\star}$ & 1.3 & 58.4 & 5.5 & 52.6 & 8.0 \\
\hline CD3+ CD8+ & $14 \cdot 7$ & 1 & 14.5 & $2 \cdot 6$ & $32 \cdot 3$ & 3.6 & $47 \cdot 7$ & $10 \cdot 3$ \\
\hline Total CD45RA+ & 41.8 & 1.8 & $45 \cdot 3$ & 3.5 & 123.6 & $12 \cdot 9$ & $141 \cdot 3$ & $15 \cdot 5$ \\
\hline CD3+:CD45+ ratio & 1.04 & 0.09 & 0.84 & 0.06 & 0.94 & 0.06 & 0.93 & 0.10 \\
\hline Total IgM+ & $52 \cdot 0$ & 1.8 & $52 \cdot 8$ & 4.1 & $129 \cdot 2$ & $15 \cdot 4$ & $171 \cdot 2$ & $32 \cdot 8$ \\
\hline Total lgG+ & 11.9 & 1.6 & 6.4 & 1.9 & 45.5 & 4.8 & 21.4 & 3.8 \\
\hline Total lgA+ & 8.6 & 0.3 & $7 \cdot 1^{*}$ & 0.6 & 23.4 & 1.2 & $22 \cdot 7$ & 3.9 \\
\hline
\end{tabular}

$\mathrm{CD}$, cluster of differentiation.

* Mean values within a row are significantly different from the ChS group $(P<0.05)$

$\dagger$ The total number of immune cells was calculated by multiplying the percentage of immune cell phenotype in the spleen by the total number of splenocytes isolated $\left(\times 10^{6}\right)$.

$\ddagger n$ Refers to the number of dams as they are the experimental unit. This includes two offspring pooled to obtain a measure for each dam, with measurements from each offspring conducted in duplicate.

Table 7. Splenocyte T and B lymphocyte phenotypes from 10-week-old offspring fed a choline-sufficient (as free choline) diet for 10 weeks (ChS-ChS) or offspring from dams fed a choline-devoid diet during the suckling period and then fed a choline-sufficient diet for the remaining 7 weeks (ChD-ChS) (Mean values with their standard errors)

\begin{tabular}{|c|c|c|c|c|c|}
\hline \multirow[b]{2}{*}{$n \dagger$} & \multicolumn{2}{|c|}{ ChS-ChS (9) } & \multicolumn{2}{|c|}{ ChD-ChS (5) } & \multirow[b]{2}{*}{ Representative population } \\
\hline & Mean & SEM & Mean & SEM & \\
\hline \multicolumn{6}{|c|}{$\%$ of CD4+ T cells } \\
\hline CD25+ & $30 \cdot 7$ & 1.0 & $27 \cdot 2$ & $2 \cdot 2$ & CD4+ T cells expressing IL-2 receptor \\
\hline CD28+ & $90 \cdot 2$ & 0.8 & 79.5 & 5.4 & CD4+ T cells expressing co-stimulatory molecule \\
\hline$\alpha \mathrm{E} \beta 7+(\mathrm{O} \times 62+)$ & 9.5 & 1.2 & 10.5 & 0.7 & $\mathrm{CD} 4+\mathrm{T}$ cells with gut homing potential expressing the $a \mathrm{E} 2$ integrin \\
\hline CD25+ FoxP3+ & 9.8 & 1.0 & 11.4 & 1.0 & Regulatory $\mathrm{T}$ cells \\
\hline \multicolumn{6}{|c|}{$\%$ of CD8+ $\mathrm{T}$ cells } \\
\hline CD25+ & $9 \cdot 3$ & 0.8 & 11.7 & 3.5 & CD8+ T cells expressing IL-2 receptor \\
\hline CD28+ & $85 \cdot 2$ & 2.5 & $54 \cdot 0^{*}$ & 4.0 & CD8+ T cells expressing co-stimulatory molecule \\
\hline$\alpha \mathrm{E} \beta 7+(\mathrm{OX} 62+)$ & $10 \cdot 6$ & $1 \cdot 2$ & $10 \cdot 3$ & 0.8 & CD8+ T cells with gut homing potential expressing the $a$ E2 integrin \\
\hline \multicolumn{6}{|c|}{$\%$ of CD45RA+ B cells } \\
\hline $\mathrm{MHClI}+(\mathrm{OX} 6+) \ddagger$ & $88 \cdot 7$ & 3.7 & 89.5 & 3.4 & B cells with antigen presenting capacity expressing MHC Class II \\
\hline
\end{tabular}

$\mathrm{CD}$, cluster of differentiation.

* Mean values within a row is significantly different from the ChS group $(P<0.05)$.

$\dagger n$ Refers to the number of dams as they are the experimental unit. This includes two offspring pooled to obtain a measure for each dam, with measurements from each offspring conducted in duplicate.

$\ddagger \%$ of CD45RA+ cells expressing OX6+ calculated using total OX6+ cells-OX6+OX62+ to represent population of CD45RA+ cells expressing OX6+.

stimulated ex vivo with LPS, ChD offspring produced significantly lower amounts of IL- $1 \beta$ following LPS stimulation $(P<0.05)$ (Fig. 3(a)), with no difference in other cytokines (IL-6, IL-10, IFN- $\gamma$ and TNF- $\alpha$ ) following LPS stimulation (data not shown). Following stimulation with CD3/CD28, a T cell antigen, ChD offspring produced significantly lower amounts of IFN- $\gamma$ compared with ChS offspring (Fig. 3(b)). There was no significant difference in other cytokines (IL-2, IL-6, IL-10 and TNF- $\alpha$ ) following CD3/CD28 stimulation (data not shown). With mitogen ConA, there was no significant difference in cytokine production (IL-2, IL-6, IL-10, IFN- $\gamma$ and TNF- $\alpha$ ) between the ChD and ChS diet groups (data not shown). At 10 weeks, when splenocytes were stimulated ex vivo with ConA or LPS, ChD-ChS offspring produced significantly lower amounts of IL-6 compared with ChS-ChS offspring $(P<0.05)$ (Fig. 3(c) and $(d))$. There was no significant difference in cytokine production (IL- $1 \beta$, IL-2, IL-10, IFN- $\gamma$ and TNF- $\alpha$ ) when stimulated with ConA or LPS between the ChD-ChS and the ChS-ChS diet groups (data not shown). There was no significant correlation between IL-2 production and lymphocyte subsets (online Supplementary Table S1). However, when IL-2 was expressed on the basis of the number of lymphocytes thought to be involved in producing this cytokine, there was a significantly lower amount of IL-2 when expressed in relation to the number of CD4+ CD25+ cells and total T cells (CD4+ and CD8+ cells) expressing CD25+ in the ChD offspring (online Supplementary Table S2).

\section{Plasma concentrations of cytokines, chemokines and haptoglobin}

Plasma haptoglobin concentrations were significantly lower in ChD offspring compared with ChS offspring $(P<0.05)$ 
(Fig. 4(a)); however, there was no difference in plasma haptoglobin between ChD-ChS and ChS-ChS offspring at 10 weeks (Fig. 4(b)). Plasma concentrations of TNF- $\alpha$ and

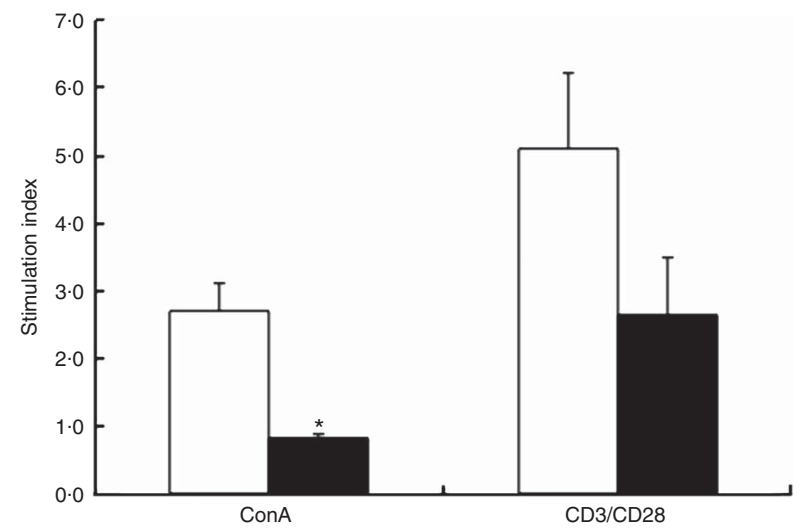

Fig. 2. Response of spleen lymphocytes from the subset of 3-week-old offspring from dams fed choline-sufficient (as free choline) (ChS, $\square ; n 3$ ) or choline-devoid $(\mathrm{ChD}, \mathbf{\square} ; n 2)$ diets during the suckling period. Stimulation index: amount of $\left[{ }^{3} \mathrm{H}\right]$ thymidine uptake (dpm) in the presence of each mitogen divided by the amount of $\left[{ }^{3} \mathrm{H}\right]$ thymidine uptake $(\mathrm{dpm})$ in the absence of each mitogen. This includes two offspring pooled to obtain a measure for each dam, with measurements from each offspring conducted in triplicate. ConA, concanavalin $\mathrm{A} ; n$, the number of dams as they are the experimental unit. * Mean value was significantly different from that of the choline-sufficient group $(\mathrm{ChS})(\mathrm{P}<0.05)$.
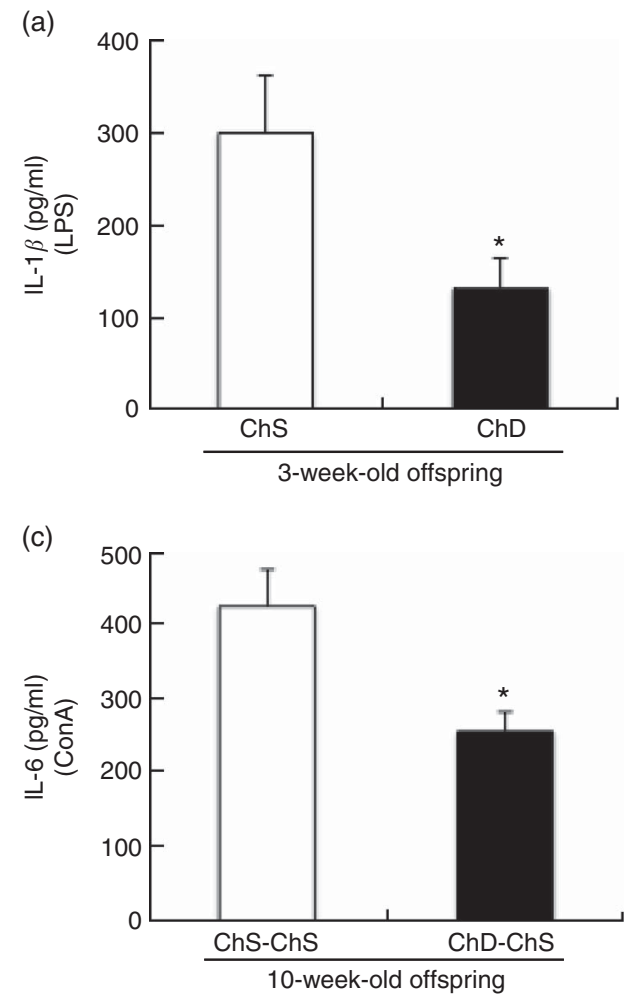

KC/GRO were not significantly different between ChS and ChD offspring at 3 weeks of age nor were concentrations different between ChS-ChS and ChD-ChS offspring at 10 weeks of age (data not shown). Circulating plasma concentrations of IFN- $\gamma$, IL-10, IL-13, IL-1 $\beta$, IL-4, IL-5 and IL-6 were all below detection levels for both 3-week-old and 10-week-old offspring.

\section{Discussion}

We have demonstrated that endogenous choline synthesis is not sufficient to meet the offspring's needs for growth and immune system development, and a dietary source is needed in the maternal diet. Consistent with findings from Dellschaft et $a l .{ }^{(16)}$, the absence of choline in the diet during the lactation period resulted in stunted growth likely due to both the reduced supply of choline and the reduced delivery of other essential nutrients owing to a lower intestinal surface area in the pup ${ }^{(28)}$. In support of this, plasma haptoglobin concentrations were lower in ChD offspring, suggestive of general malnutrition ${ }^{(29)}$. Although conducted in two separate experiments, and therefore invalid for assessment of statistical differences, our studies suggest that providing a ChS diet after weaning reversed some of the negative effects on growth with a ChD in early life. A ChD during suckling significantly reduced offspring growth, but providing choline in the weaning diet enabled catch-up growth to occur, as the mean final body weights of the ChD-ChS (b)

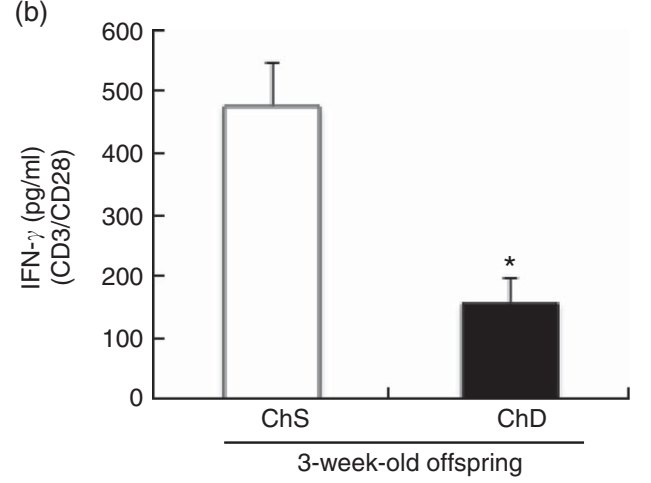

(d)

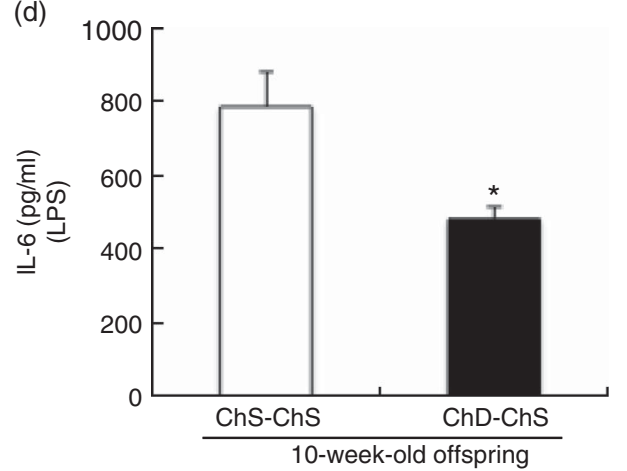

Fig. 3. Ex vivo mitogen-stimulated splenocyte cytokine production from 3-week-old offspring (choline-sufficient diet (ChS) and choline-deficient diet (ChD)) (a, b) and 10-week-old offspring (ChS-ChS and ChD-ChS) (c, d). CD3/CD28 stimulation performed in a subset of animals: ChS ( $n$ 5), ChD ( $n$ 4). The amount IL-2 in the media after LPS stimulation was below detection levels. IL-1 $\beta$ was only measured in the supernatant of LPS-stimulated cells. Cytokine concentrations in spleen supernatant $(\mathrm{pg} / \mathrm{ml})$ after 48 -h of culture with mitogen. Each of the measures were conducted in duplicate for each of the two offspring for a dam (CV $<10 \%)$. The $n$ represents the mean of two offspring of a dam. * Mean values were significantly different from the choline-sufficient group (ChS or ChS-ChS) $(P<0.05)$. CD, cluster of differentiation; ConA, Concanavalin A; LPS, lipopolysaccharide. 
(a)

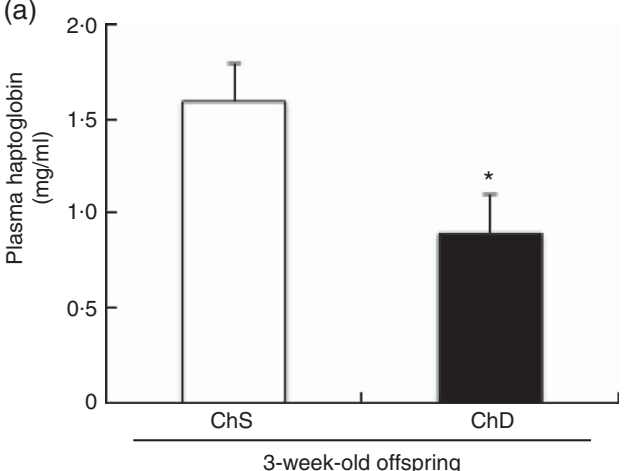

(b)

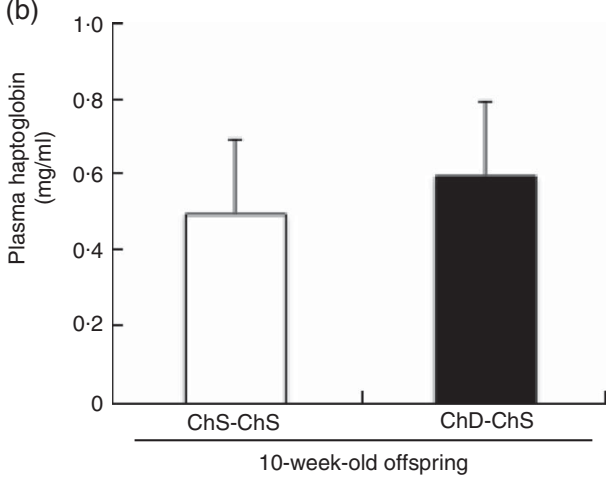

Fig. 4. Plasma concentrations of haptoglobin in 3-week-old offspring (choline-sufficient diet (ChS) and choline-deficient diet (ChD)) (a) and 10-week-old offspring (ChS-ChS and ChD-ChS) (b). Discrepancies between total number of offspring and the number available for measurements of haptoglobin, TNF- $a$ and keratinocyte chemoattractant/human growth-regulated oncogene (KC/GRO) are due to sample errors. ${ }^{*}$ Mean values were significantly different from $\mathrm{ChS}$ group $(P<0.05)$.

offspring were similar to those of the ChS-ChS offspring at 10 weeks of age. This is consistent with a previous study in which maternal dietary lipotrope deficiency (choline, methionine and vitamin $\mathrm{B}_{12}$ ) resulted in low birth and weaning weights, but a switch to a lipotrope-sufficient diet at weaning corrected body weights at 14 weeks after weaning ${ }^{(30)}$. Similarly, a ChS in the weaning period appeared to reverse the symptoms of malnutrition (lymphopenia and lower mean haptoglobin concentration) that occurred with a $\mathrm{ChD}$ in the suckling period. A choline-devoid during in the suckling period reduced the proportion of $\mathrm{B}$ cells in the spleen of the offspring. However, a ChS diet in the weaning period appeared to reverse these reductions, with similar proportions of $\mathrm{B}$ cells in spleen of offspring in both groups at the end of 10 weeks. ChD-ChS also had similar IFN- $\gamma$ and IL- $1 \beta$ production compared with ChS-ChS offspring. This suggests that the effect of a lower dietary supply of choline during suckling on B cells is reversible by providing what is currently believed to be adequate choline in the weaning diet. Further research is needed to identify the mechanism for the role of choline in $\mathrm{B}$ cell function and development during the suckling period.

This study demonstrated that not providing choline in the maternal diet resulted in indicators of lymphopenia in 3-weekold offspring, demonstrated by 34 and $46 \%$ lower number of CD4+ T lymphocytes and B lymphocytes, respectively, similar to what has been reported for other micronutrient deficiencies $\left(\mathrm{Zn}^{(31)}\right.$ and folate $\left.{ }^{(32)}\right)$. As the suckling period is a time of rapid cellular expansion $^{(12)}$, this may have significant consequences on later immune function. Interestingly, despite a lower total number of lymphocytes, assessment of $\mathrm{T}$ cell activation markers (CD25, CD28, CD152) revealed a more activated phenotype in ChD offspring compared with the ChS offspring. ChD offspring had a higher proportion of CD4+ cells expressing CD28. CD28 expression is critical for the interaction of $\mathrm{T}$ cells with antigenpresenting cells ${ }^{(33)}$ and suggests a more activated and stimulated $\mathrm{CD} 4+$ population. There was a higher proportion of CD8+ and CD4+ cells from ChD offspring that expressed the transferrin receptor (CD71), which is involved in cellular Fe uptake and expression, also suggesting cellular activation ${ }^{(34)}$. However, despite an activated phenotype, splenocytes from ChD offspring had a significantly lower ex vivo proliferative response (stimulation index) to ConA, a polyclonal $\mathrm{T}$ cell mitogen. ChD offspring had a higher proportion of activated $\mathrm{T}$ cells and T cells expressing the IL-2 receptor (CD25), yet there was no difference in IL-2 production after either ConA or CD3/ CD28 stimulation. Higher proportions of CD8+ CD25+ have been shown to supress IL-2 response ${ }^{(35)}$; therefore, this immunosuppression may explain why there was no difference in IL-2 production after stimulation. When the production of IL-2 was expressed on the basis of the number of T lymphocytes expressing the IL-2 receptor (CD25), we observed a significantly lower IL-2 per CD4+ CD25+ lymphocytes in ChD offspring. This suggests that the lymphocytes from $\mathrm{ChD}$ offspring may also have reduced ability to synthesise IL-2. Furthermore, ChD offspring had a higher proportion of CD8+ T cells expressing CD152 (cytotoxic T-lymphocyte antigen-4 (CTLA-4), which is a well-characterised co-receptor involved in the regulation of $\mathrm{T}$ cell response $\mathrm{s}^{(36,37)}$ that could negatively affect the development of the immune system. CTLA- 4 can also be expressed intracellularly, and recently has been demonstrated to play a role in the function of Tregs ${ }^{(38)}$; therefore, future studies should examine both surface and intracellular expressions of this protein.

As the proliferative response to $\mathrm{CD} 3 / \mathrm{CD} 28$, a mitogen that directly stimulates $\mathrm{T}$ cells via the $\mathrm{T}$ cell receptor, was not significantly different, our results suggest that the altered ex vivo function may be related to both impaired $\mathrm{T}$ cells that do not function as well (on a cell per cell basis) and the lower number of B cells (accessory cells). Similar to what we reported in dams fed the ChD diet ${ }^{(16)}$, ChD offspring have reduced capacity to produce IFN- $\gamma$ following CD3/CD28 stimulation. Production of IFN- $\gamma$ is critical for inhibiting the differentiation and activation of T helper 2 (Th2) cells and promoting a Th1 response. Skewing towards a Th1 response is indicative of immune system maturation in both humans and rodents ${ }^{(12)}$. Inappropriate Th2 response in early development has been indicated to play a role in the production of allergic inflammation and predisposition towards allergy ${ }^{(14)}$. Insufficient IFN- $\gamma$ is also associated with increased incidence of infection among newborns ${ }^{(39)}$. This combined with a higher Th2 response would be predicted to impair the ability of the immune system to respond appropriately to challenges. This is supported by previous research 
that has shown that choline insufficiency results in impaired $\mathrm{T}$ cell functions. More specifically, in adult rodents, dietary choline deficiency has been shown to reduce lymphocyte proliferation $^{(15)}$, which was accompanied by depression of T cell function. Similarly, 5-month-old offspring from dams fed a choline-methionine-deficient diet during lactation had a decreased stimulation index with ConA or phytohemagglutinin stimulation and greater mortality from a bacterial infection of S. typhimurium ${ }^{(40)}$

We also have evidence from this study that not providing choline in the maternal diet during suckling may alter the ability of offspring to respond to bacterial antigens. Following ex vivo stimulation with LPS, a bacterial antigen, ChD offspring produced a lower amount of IL- $1 \beta$. Inadequate production of IL- $1 \beta$ would increase the susceptibility to intracellular pathogens $^{(41)}$ and reduce the Th1 and Th17 response by $\mathrm{T}$ cells ${ }^{(34)}$. As LPS stimulates antigen-presenting cells including macrophages, B cells and dendritic cells, it is possible that cytokine production in response to LPS stimulation can be attributed to other immune cells, in addition to $\mathrm{T}$ cells. However, as the observed changes in immune cell populations (Tables 4 and 5) at 3 weeks of age were primarily in the $\mathrm{T}$ lymphocyte population, it is likely that the lymphocyte population had the most profound effect on cytokine production.

Furthermore, this study demonstrates for the first time that insufficient maternal dietary choline during the suckling period results in alterations in the expansion and maturation of the $\mathrm{T}$ cell population and the ability to respond to mitogens later in life. Feeding a ChS diet during weaning rescued the lymphopenic status of the ChD offspring at 3 weeks. However, female offspring from dams fed a ChD diet during suckling had a slight shift in lymphocyte proportions at 10 weeks, displaying a lower proportion of CD4+ T cells and lower IL- 6 production after ConA or LPS stimulation. Expansion of the CD4+ population is a critical developmental process that occurs during the suckling period $^{(42)}$ and IL-6 has been demonstrated to play a role in this process. IL- 6 induces proliferation of $\mathrm{T}$ cells in an IL-2-independent manner ${ }^{(43)}$, promoting differentiation of the CD4+ and CD8+ populations ${ }^{(44)}$ and the ability of $\mathrm{T}$ cells to communicate with accessory cells (B cells) ${ }^{(45)}$. Therefore, it appears that it is not only the number of CD4+ cells but also their ability to produce an important cytokine that is affected by maternal choline intake during suckling. In addition, ChD-ChS offspring had a lower proportion of cytotoxic T cells expressing the co-stimulatory molecule CD28, also used as a maturation marker. The reduced proportion of mature $\mathrm{T}$ cells may be in part responsible for the impaired ex vivo IL-6 response observed when stimulated. A source of choline has been demonstrated to be essential for macrophage production of IL-6 ${ }^{(46)}$. Although the proportion of macrophages (CD284+ CD11+) was not altered between the diet groups, reduced IL-6 production may be attributed to impaired macrophage function in addition to $\mathrm{T}$ cell function. In the experiment examining the effects of a maternal diet devoid of choline in 3-week-old offspring, we did not examine the possible influence of sex as one male and one female offspring were used for each dam. To our knowledge, there have been no studies examining the difference in choline requirements between sexes in young animals (i.e. during suckling), but previously we did not find an effect of sex on immune cell phenotypes in animals at this age $^{(20)}$. The experiment examining the long-term effects of choline-devoid maternal diet during lactation was conducted on female offspring only. It has been shown that female mice, at sexual maturity, have greater synthesis of PC through the PEMT pathway $^{(47)}$, and mature female rodents are less susceptible to the consequences of low dietary choline compared with male rodents ${ }^{(48,49)}$. It would be logical to follow-up our findings with male offspring in both studies as we may see a larger programming effect in an animal that has a lower ability to endogenously synthesise choline.

The impaired $\mathrm{T}$ cell-mediated functions and maturation observed in both $\mathrm{ChD}$ and $\mathrm{ChD}$-ChS offspring are supported by previous studies demonstrating that choline $\mathrm{e}^{(16)}$ or lipotrope deficiency (including choline) ${ }^{(15)}$ has the most profound effect on the $\mathrm{T}$ cell component of the immune system. This impaired $\mathrm{T}$ cell function may increase the susceptibility to infection later in life. Newberne et al. demonstrated that when offspring from dams fed a marginally $\mathrm{ChD}$ diet during suckling were placed on a ChS diet after weaning, they were still more susceptible to $S$. typhimurium infection at $100 \mathrm{~d}$ after weaning compared with offspring fed a ChS diet. However, Nauss et al. ${ }^{(18)}$ suggests that age plays a role in the function of the immune system in the context of a methionine-choline-deficient diet. Rats fed a marginally methionine-choline-deficient diet (67\% lower in methionine and choline compared with control diet) during weaning were most susceptible to $S$. typhimurium infection at a younger age (3 weeks after weaning) compared with older animals ( 3 and 12 months after weaning). Younger animals also had the lowest amount of lymphocyte proliferation compared with older animals on the same marginally deficient diet. Our results suggest that maternal choline deficiency during the suckling period may impair the development of the $\mathrm{T}$ cell population later in life, perhaps with greater effects in the early post-weaning period. Our study focused primarily on surrogate markers of immune function (ex vivo cytokine production, $\left[{ }^{3} \mathrm{H}\right]$ thymidine uptake and cellular proliferation). As previous studies have found an effect of choline deficiency on T-cell-mediated functions ${ }^{(15)}$, future studies should examine not only surrogate markers of immune function but also more specific immune challenges such as susceptibility to infection and DTH response to examine $\mathrm{T}$ cell functions and tests that have greater applicability to humans. In addition, we did not perform the proliferation assay on the 10-week-old offspring. In the 10-week-old offspring, there was lower IL-6 production in the offspring from the dams fed the $\mathrm{ChD}$ diet, with similar amounts of IL-2 produced compared with the offspring from dams fed the ChS diet during suckling. IL-6 has been demonstrated as a potent regulator and stimulator of lymphocyte proliferation, independent of the proliferation actions associated with $\mathrm{IL}-2^{(43,50)}$. In addition, the ChD-ChS offspring had a lower proportion of CD3+ CD4+ and markers indicating activation (CD28+). Therefore, we would predict that the ChD-ChS offspring would have a lower proliferative response following stimulation that is associated with the lower IL- 6 production when stimulated with ConA or LPS.

We demonstrated that choline is essential in the maternal diet to support offspring growth and development of the immune 
system. Maternal choline deficiency during a critical period of development stunted growth and resulted in lymphopenia, which may have contributed to the impaired $\mathrm{T}$ and $\mathrm{B}$ cell responses in the offspring at the end of suckling. The long-term consequences of a lower supply of choline during this critical period of development resulted in a lower expansion of the CD4+ population and a lower ability to produce IL-6, even after choline was fed in the weaning diet. Together, with findings of a possible suboptimal intake during the lactation period in humans, future research should focus on identifying potential benefits of increasing total choline in the maternal diet to support immune development in infants.

\section{Acknowledgements}

The authors acknowledge the technical assistance of Nicole Coursen, Marnie Newell, Yuan Yuan Zhao and Howe-Ming Yu.

Funding for this project came from the Natural Sciences and Engineering Council of Canada (NSERC RGPIN 121610, 386652 and 03932) and Quality Food for Health grant from the ALMA, Alberta Innovates Biosolutions and the Egg Farmers of Alberta (2012Q005R). E. D. L. is a recipient of an Izaak Walton Killam Memorial Scholarship and a Natural Sciences and Engineering Research Council Postgraduate Doctoral Scholarship. C. R. is a recipient of postdoctoral fellow scholarships from Canadian Institutes of Health Research (CIHR), Fonds de Recherche en Santé du Québec and Izaak Walton Killam Memorial Postdoctoral Fellowships. R. L. J. is a CIHR New Investigator. None of the mentioned funders had a role in the design, analysis or writing of this article.

C. J. F., J. M. C. and R. L. J. designed the study; E. D. L., S. G. and N. S. D. conducted the study; E. D. L. and C. R. analysed the data and performed statistical analysis; E. D. L. and C. J. F. wrote the paper; C. J. F. has primary responsibility for final content. All the authors have read and approved the final manuscript.

There are no conflicts of interest.

\section{Supplementary material}

For supplementary material/s referred to in this article, please visit http://dx.doi.org/doi:10.1017/S0007114516002919

\section{References}

1. Zeisel SH \& da Costa KA (2009) Choline: an essential nutrient for public health. Nutr Rev 67, 615-623.

2. Hove EL \& Copeland DH (1954) Progressive muscular dystrophy in rabbits as a result of chronic choline deficiency. J Nutr 53, 391-405.

3. Zeisel SH (2004) Nutritional importance of choline for brain development. J Am Coll Nutr 23, 621S-626S.

4. Lewis ED, Subhan FB, Bell RC, et al. (2014) Estimation of choline intake from $24 \mathrm{~h}$ dietary intake recalls and contribution of egg and milk consumption to intake among pregnant and lactating women in Alberta. Br J Nutr 112, 112-121.

5. Gossell-Williams M, Fletcher H, McFarlane-Anderson $\mathrm{N}$, et al. (2005) Dietary intake of choline and plasma choline concentrations in pregnant women in Jamaica. West Indian Med J 54, 355-359.
6. Molloy AM, Mills JL, Cox C, et al. (2005) Choline and homocysteine interrelations in umbilical cord and maternal plasma at delivery. Am J Clin Nutrn 82, 836-842.

7. Ilcol YO, Ozbek R, Hamurtekin E, et al. (2005) Choline status in newborns, infants, children, breast-feeding women, breastfed infants and human breast milk. J Nutr Biochem 16, 489-499.

8. Gwee MC \& Sim MK (1979) Changes in the concentration of free choline and cephalin- $N$-methyltransferase activity of the rat material and foetal liver and placeta during gestation and of the maternal and neonatal liver in the early postpartum period. Clin Exp Pharmacol Physiol 6, 259-265.

9. Burdge GC, Hunt AN \& Postle AD (1994) Mechanisms of hepatic phosphatidylcholine synthesis in adult rat: effects of pregnancy. Biochem J 303, 941-947.

10. Zeisel SH, Mar MH, Zhou Z, et al. (1995) Pregnancy and lactation are associated with diminished concentrations of choline and its metabolites in rat liver. J Nutr 125, 3049-3054.

11. Caudill MA (2010) Pre- and postnatal health: evidence of increased choline needs. J Am Diet Assoc 110, 1198-1206.

12. Perez-Cano FJ, Franch A, Castellote C, et al. (2012) The suckling rat as a model for immunonutrition studies in early life. Clin Dev Immunol 2012, 537310.

13. Field CJ (2005) The immunological components of human milk and their effect on immune development in infants. J Nutr 135, 1-4.

14. Calder PC (2007) Immunological parameters: what do they mean? J Nutr 137, 773S-780S.

15. Courreges MC, Benencia F, Uceda A, et al. (2003) Effect of dietary choline deficiency on immunocompetence in Wistar rats. Nutr Res 23, 519-526.

16. Dellschaft NS, Ruth MR, Goruk S, et al. (2015) Choline is required in the diet of lactating dams to maintain maternal immune function. Br J Nutr 113, 1723-1731.

17. Newberne PM, Wilson RB \& Williams G (1970) Effects of severe and marginal lipotrope deficiency on response of postnatal rats to infection. Br J Exp Pathol 51, 229-235.

18. Nauss KM, Connor AM, Kavanaugh A, et al. (1982) Alterations in immune function in rats caused by dietary lipotrope deficiency: effect of age. J Nutr 112, 2333-2341.

19. Reeves PG (1997) Components of the AIN-93 diets as improvements in the AIN-76A diet. J Nutr 127, 838S-841S.

20. Field CJ, Goruk S \& Glen S (1999) Effect of diet on the development of the immune system in the BB Rat. J Clinl Biochem Nutr 26, 119-134.

21. Zhao YY, Xiong Y \& Curtis JM (2011) Measurement of phospholipids by hydrophilic interaction liquid chromatography coupled to tandem mass spectrometry: the determination of choline containing compounds in foods. $J$ Chromatogr A 1218, 5470-5479.

22. Xiong Y, Zhao YY, Goruk S, et al. (2012) Validation of an LC-MS/MS method for the quantification of choline-related compounds and phospholipids in foods and tissues. $J$ Chromatogr B Analyt Technol Biomed Life Sci 911, 170-179.

23. Field CJ, Wu G, Metroz-Dayer MD, et al. (1990) Lactate production is the major metabolic fate of glucose in splenocytes and is altered in spontaneously diabetic BB rats. Biochem J 272, 445-452.

24. Field CJ, Thomson CA, Van Aerde JE, et al. (2000) Lower proportion of CD45R0 + cells and deficient interleukin-10 production by formula-fed infants, compared with human-fed, is corrected with supplementation of long-chain polyunsaturated fatty acids. J Pediatr Gastroenterol Nutr 31, 291-299.

25. Woollett GR, Barclay AN, Puklavec M, et al. (1985) Molecular and antigenic heterogeneity of the rat leukocyte-common antigen from thymocytes and $\mathrm{T}$ and B lymphocytes. Eur $J$ Immunol 15, 168-173. 
26. Blewett HJ, Gerdung CA, Ruth MR, et al. (2009) Vaccenic acid favourably alters immune function in obese JCR:LA-cp rats. Br J Nutr 102, 526-536.

27. Field CJ, Van Aerde JE, Robinson LE, et al. (2008) Effect of providing a formula supplemented with long-chain polyunsaturated fatty acids on immunity in full-term neonates. Br J Nutr 99, 91-99.

28. da Silva RP, Kelly KB, Lewis ED, et al. (2015) Choline deficiency impairs intestinal lipid metabolism in the lactating rat. J Nutr Biochem 26, 1077-1083.

29. Sadrzadeh SM \& Bozorgmehr J (2004) Haptoglobin phenotypes in health and disorders. Am J Clin Pathol 121, Suppl., S97-S104.

30. Newberne PM, Ahlstrom A \& Rogers AE (1970) Effects of maternal dietary lipotropes on prenatal and neonatal rats. J Nutr 100, 1089-1097.

31. Hosea HJ, Rector ES \& Taylor CG (2004) Dietary repletion can replenish reduced $\mathrm{T}$ cell subset numbers and lymphoid organ weight in zinc-deficient and energy-restricted rats. Br J Nutr 91, 741-747.

32. Williams ML, Shoot RJ, O'Neal PL, et al. (1975) Role of dietary iron and fat on vitamin E deficiency anemia of infancy. $N$ Engl J Med 292, 887-890.

33. Thompson CB, Lindsten T, Ledbetter JA, et al. (1989) CD28 activation pathway regulates the production of multiple T-cellderived lymphokines/cytokines. Proc Natl Acad Sci U S A 86, 1333-1337.

34. Reddy M, Eirikis E, Davis C, et al. (2004) Comparative analysis of lymphocyte activation marker expression and cytokine secretion profile in stimulated human peripheral blood mononuclear cell cultures: an in vitro model to monitor cellular immune function. J Immunolo Met 293, 127-142.

35. McNally A, Hill GR, Sparwasser T, et al. (2011) CD4+ CD25+ regulatory $\mathrm{T}$ cells control CD8+ T-cell effector differentiation by modulating IL-2 homeostasis. Proc Natl Acad Sci U S A 108, 7529-7534.

36. Rudd CE (2009) CTLA-4 co-receptor impacts on the function of Treg and CD8+ T-cell subsets. Eur J Immunol 39, 687-690.

37. Rudd CE, Taylor A \& Schneider H (2009) CD28 and CTLA-4 coreceptor expression and signal transduction. Immunol Rev 229, $12-26$

38. Wing K, Onishi Y, Prieto-Martin P, et al. (2008) CTLA-4 control over Foxp3+ regulatory T cell function. Science 322, 271-275.
39. Kotiranta-Ainamo A, Rautonen J \& Rautonen N (2004) Imbalanced cytokine secretion in newborns. Biol Neonate 85, 55-60.

40. Williams EA, Gebhardt BM, Morton B, et al. (1979) Effects of early marginal methionine-choline deprivation on the development of the immune system in the rat. Am J Clin Nutr 32, 1214-1223

41. Hunter CA, Chizzonite R \& Remington JS (1995) IL-1 beta is required for IL-12 to induce production of IFN-gamma by NK cells. A role for IL-1 beta in the T cell-independent mechanism of resistance against intracellular pathogens. J Immunol $\mathbf{1 5 5}$, 4347-4354.

42. Perez-Cano FJ, Castellote C, Marin-Gallen S, et al. (2007) Phenotypic and functional characteristics of rat spleen lymphocytes during suckling. Dev Comp Immunol 31, 1264-1277.

43. Lotz M, Jirik F, Kabouridis P, et al. (1988) B cell stimulating factor 2/interleukin 6 is a costimulant for human thymocytes and T lymphocytes. J Exp Med 167, 1253-1258.

44. Okada M, Kitahara M, Kishimoto S, et al. (1988) IL-6/BSF-2 functions as a killer helper factor in the in vitro induction of cytotoxic T cells. J Immunol 141, 1543-1549.

45. Eddahri F, Denanglaire S, Bureau F, et al. (2009) Interleukin6/STAT3 signaling regulates the ability of naive $\mathrm{T}$ cells to acquire B-cell help capacities. Blood 113, 2426-2433.

46. Tian Y, Pate C, Andreolotti A, et al. (2008) Cytokine secretion requires phosphatidylcholine synthesis. J Cell Biol 181, 945-957.

47. Noga AA \& Vance DE (2003) A gender-specific role for phosphatidylethanolamine $\quad N$-methyltransferase-derived phosphatidylcholine in the regulation of plasma high density and very low density lipoproteins in mice. J Biol Chem $\mathbf{2 7 8}$, 21851-21859.

48. Tessitore L, Sesca E, Greco M, et al. (1995) Sexually differentiated response to choline in choline deficiency and ethionine intoxication. Int J Exp Pathol 76, 125-129.

49. Saito R, Palomba L, Rao KN, et al. (1991) Resistance of female Fischer-344 rats to the hepatonecrogenic and hepatocarcinogenic actions of a choline-devoid diet. Carcinogenesis 12, 1451-1457.

50. Holsti MA \& Raulet DH (1989) IL-6 and IL-1 synergize to stimulate IL-2 production and proliferation of peripheral T cells. J Immunol 143, 2514-2519.

51. Bernhart FW \& Tomarelli RM (1966) A salt mixture supplying the national research council estimates of the mineral requirements of the rat. $J$ Nutr $\mathbf{8 9}, 495-500$. 